\title{
Anti-obesity effects of a mixed extract containing Platycodon grandiflorum, Apium graveolens and green tea in high-fat-diet-induced obese mice
}

\author{
BYOUNG OK CHO ${ }^{1,2}$, JIWON CHOI ${ }^{3}$, HYUN JU KANG ${ }^{1}$, DENIS NCHANG CHE ${ }^{2,4}$, \\ JAE YOUNG SHIN ${ }^{1,5}$, JI-SU KIM ${ }^{2,5}$, SANG JUN KIM ${ }^{6}$ and SEON IL JANG ${ }^{1,2}$ \\ ${ }^{1}$ Research Institute, Ato Q\&A Co. Ltd., Jeonju, Jeonbuk 54840; Departments of ${ }^{2}$ Health Management and \\ ${ }^{3}$ Radiological Sciences, Jeonju University, Jeonju, Jeonbuk 55069; ${ }^{4}$ Department of Food Science and Technology, \\ Chonbuk National University, Jeonju, Jeonbuk 54896; ${ }^{5}$ Department of Agro-Bio and Food Industry, \\ Jeonju University, Jeonju, Jeonbuk 55069; ${ }^{6}$ Functional Food (Drug) R\&D Team, Jeonju \\ AgroBio-Materials Institute, Jeonju, Jeonbuk 54810, Republic of Korea
}

Received April 17, 2019; Accepted September 9, 2019

DOI: $10.3892 /$ etm.2020.8493

\begin{abstract}
The anti-obesity effect of a combination of extracts made of Platycodon grandiflorum (PGE), Apium graveolens (AGE) and green tea (GTE) extracts was investigated in a high-fat diet-induced obese C57BL/6N mouse model. Body weight, epididymal adipose tissue weight, liver weight, adipocytes size and serum lipid profile, insulin, leptin and glucose levels were investigated. Additionally, hepatic steatosis, injury and oxidative burden were evaluated in the present study. The current study demonstrated that the PGE, AGE, and GTE (PAG) mixture were most effective in preventing obesity and its associated complications compared with the single extracts used alone. This was evidenced by the PAG's prevention of weight gain, reduction of adipocyte size, beneficial effects in serum lipid profile, levels of insulin, leptin and glucose, and the prevention of liver injury by reducing fat accumulation in the liver, decreased GOT and GPT enzymes and the upregulation of liver antioxidant enzymes. These results suggested that PAG may provide insights into functional food ingredients for use in the prevention of obesity.
\end{abstract}

\section{Introduction}

Obesity is a metabolic disease that has emerged over the past 3 decades as a major health drawback. The most recent data estimate that more than 1.9 billion adults of over the age of 18 are overweight, with over 650 million of them

Correspondence to: Professor Seon Il Jang, Department of Health Management, Jeonju University, 303 Cheonjam-ro, Wansan-gu, Jeonju, Jeonbuk 55069, Republic of Korea

E-mail: sonjjang@jj.ac.kr

Key words: obesity, Platycodon grandiflorum, Apium graveolens, green tea, synergistic effects being obese (1). In addition, while just under $1 \%$ of children and adolescents aged 5-19 were obese in 1975, data in 2016 revealed that more than 124 million children and adolescents (6\% of girls and $8 \%$ of boys) were obese (2). Overweight and obesity increase the risk of many health problems. It has a harmful metabolic consequence on blood pressure, cholesterol, triglycerides, and insulin resistance, and increases the risks of coronary heart disease, ischemic stroke and type 2 diabetes mellitus (3). It is also said to increase the risk of cancer of the breast, colon, prostate, endometrium, kidney and gallbladder, and mortality rates are increased by obesity (4). Despite these complications of obesity, it is regarded as the most preventable cause of death (5). Therefore, effective management is essential.

Several prevention/treatment options are available for the treatment of obesity. The most common treatment involves losing weight through healthy eating and physical exercise. When these methods are ineffective, weight loss medicines are recommended to treat overweight and obesity. However, concerns have been raised regarding the use of weight-loss medication whose side effects may outweigh their benefits. Most anti-obesity medications that were approved and marketed have now been withdrawn due to serious adverse effects. For instance, fenfluramine and dexfenfluramine, used to treat obesity, were recalled by the U.S. Food and Drug Administration (FDA) because of concerns related to heart valve problems (6). Phentermine, diethylpropion, and mazindol were recalled by the European Medicines Agency (EMA) due to their overwhelming side effects (7). Rimonabant, a selective CB1 blocker used to treat obesity that was available in 56 countries was never approved by the FDA and was recalled by the EMA because of raised concerns of psychiatric adverse disorders (8). Therefore, there is a need for alternative therapy with little to no side effects on the management of obesity and its related complications. Herbal medicines have been used to control weight and treat obesity. For instance, an increasing number of clinical trials have confirmed the beneficial effects of green tea on obesity (9). The anti-obesity 
effect of green tea is associated with its caffeine and catechins, (-)-epigallocatechin-3-gallate contents (10).

Platycodon grandiflorum is a perennial plant of the Campanulaceae family used as herbal medicine for the treatment of respiratory disorders, asthma, and diabetes. It is rich in bioactive compounds including flavonoids, polyphenols, and the triterpenoid saponins, and possesses antioxidant, anticancer, anti-inflammatory, and hepatoprotective properties (11-15). Platycodins from $P$. grandiflorum showed anti-obesity effects and lowered whole body cholesterol in a study (16). Apium graveolens or celery, is a cultivated edible plant, commonly used as a vegetable and has medicinal properties spanning anti-inflammatory, antifungal, and antibacterial (17-19), and is also used to treat a variety of diseases such as asthma, hepatitis, bronchitis, and gastrointestinal infections (20). Celery has also been shown to reduce blood glucose, blood lipids, and blood pressure (21). The main functional compounds found in celery are chlorogenic acid, luteolin, apiin and apigenin (22). Green tea (Camellia sinensis) is among one of the most consumed beverages in the world. A large body of evidence points to the fact that green tea and its isolated compounds have anti-inflammatory, antibacterial, anti-viral and neuroprotective effects (9). Over the past years, the anti-obesity effects of green tea in animals and humans have been closely studied as a hot topic in functional food research. Indeed, there are clinical shreds of evidence of the beneficial effects of green tea on obesity (23-25). The main constituents of green tea are catechins with some amount of gallic acid, quercetin, kaempferol, myricetin, and chlorogenic acid (26). The continuous search for better therapies for the treatment of obesity and its associated disorders has spark growing interest in the synergistic effects of various phytochemicals and plant extracts for the treatment of obesity. In this light, we sought to investigate the synergistic effects of $P$. grandiflorum, A. graveolens, and green tea in obesity and obesity-associated disorders induced by a high-fat diet as part of our on-going project to develop anti-obesity functional food products from a combination of different extracts whose efficacy will be better than other products in the market including green tea.

\section{Materials and methods}

Plant extraction. P. grandiflorum roots and A. graveolens leaves were procured from a local market (Jeonbuk, Korea) and a local farm (Busan, Korea), respectively. The plants were washed in distilled water and dried at $40^{\circ} \mathrm{C}$ for $16 \mathrm{~h}$. The $P$. grandiflorum roots and A. graveolens leaves $(100 \mathrm{~g}$ each) were extracted in $80 \%$ ethanol $(2,000 \mathrm{ml})$, respectively for $72 \mathrm{~h}$. The extracted samples were filtered using a $0.45 \mu \mathrm{m}$ filter paper (Advantec, Togo, Japan). The filtered samples were concentrated under reduced pressure and lyophilized to obtain the dry powder of $P$. grandiflorum roots extract (PGE) and A. graveolens leaves extract (AGE), which were stored at $-20^{\circ} \mathrm{C}$ for subsequent use. Green tea extract (total catechins $\geq 38 \%$ ) was procured from Mirae Biotech Co., Ltd (Gyeonggi-do, Korea) and stored at $-20^{\circ} \mathrm{C}$ for direct use.

Animals and diet. C57BL/6N male mice (4 weeks of age) were procured from Orient Bio Inc. (Gwangju, Korea). The mice were handled and experiments were carried out based on Jeonju University Institutional Animal Care and Use Committee guidelines with permission to carry out the experiment obtained from Jeonju University (JJU-IACUC-2018-8). Following the institution's guidelines, the mice were maintained in standard environmental conditions at a temperature of $-22 \pm 2^{\circ} \mathrm{C}$, humidity of $50-60 \%$, and $12 / 12 \mathrm{~h}$ light-dark cycle. The Mice were fed with commercial standard laboratory diet and water ad libitum during an acclimatization period of 1 week. After acclimatization, the 35 mice were grouped into 7 groups and fed either with a normal diet (10\% fat) or high-fat diet (HFD) (60\% fat) for 16 weeks as follows: Group 1: Non-HFD fed group (ND), $n=5$. Group 2: HFD fed group (HFD), $\mathrm{n}=5$. Group 3: HFD with $200 \mathrm{mg} / \mathrm{kg}$ PGE treatment, $\mathrm{n}=5$. Group 4: HFD with $200 \mathrm{mg} / \mathrm{kg}$ AGE treatment, $\mathrm{n}=5$. Group 5: HFD with $200 \mathrm{mg} / \mathrm{kg}$ GTE treatment, $\mathrm{n}=5$. Group 6: HFD with $100 \mathrm{mg} / \mathrm{kg}$ PGE and $100 \mathrm{mg} / \mathrm{kg}$ AGE mixture treatment, $\mathrm{n}=5$. Group 7: HFD with $200 \mathrm{mg} / \mathrm{kg}$ PGE, AGE, and GTE mixture (1:1:1 ratio) treatment, $n=5$. The extracts were orally administered on a daily basis for 16 weeks. The ND and HFD group received an equal amount of distilled water during extract administration. All mice were euthanized at the end of the experiment by cervical dislocation. Confirmation of death was done by ensuring a firm toe pinch and lack of visible respiration. No prior death was recorded for this experiment.

Body weight gain and food intake analysis. The weight of the mice in each group was recorded at the start of the experimental period and at the end of the experiment. The average difference between the initial and final weight was taken to be the average weight gain in each group. The amount of food intake was measured at the same time on the same day of the week during the 16 weeks experimental period. The average amount of daily food intake was calculated and recorded.

Serum biochemical analysis. At the end of the 16-weeks experimental period, the mice were made to fast for $12 \mathrm{~h}$ and then were sacrificed. Blood was immediately collected through the intraorbital vein. The blood samples were centrifuged at $2,000 \mathrm{x}$ g for $15 \mathrm{~min}$ at $4^{\circ} \mathrm{C}$, and the serum was separated and stored at $-70^{\circ} \mathrm{C}$ for subsequent use. The serum concentrations of total cholesterol (TC), high-density lipoprotein cholesterol (HDL-C), triglycerides (TG) (Asan Pharmaceutical Co., Ltd., Gyeonggi, Korea), leptin (R\&D Systems, Inc., Minneapolis, MN, USA), insulin (Alpco Diagnostics, Windham, NH, USA), and glutamic oxaloacetic transaminase (GOT) and glutamic-pyruvic transaminase (GPT) (Asan Pharmaceutical Co., Ltd.) were analyzed by the use of a spectrophotometer (Tecan Group, Männedorf, Switzerland). Low-density lipoprotein cholesterol (LDL-C) was measured with the formula: LDL-C=TC-HDL-C-(TG/5). All experiments were carried out following the manufacturer's instructions. Blood glucose was measured with the aid of an Accu-Check glucometer (Roche Diagnostics, Risch-Rotkreuz, Switzerland).

Atherogenic index and cardiac risk factor measurement. The atherogenic index was measured with the formula: Atherogenic index $=(\mathrm{TC}-\mathrm{HDL}) / \mathrm{HDL}$. The cardiac risk factor was measured with the formula: Cardiac risk factor=TC/HDL. 
Liver and adipose tissue analysis. After blood collection, liver and epididymal adipose tissues were removed from the mice and weighed immediately. For liver oxidative stress analysis, $0.3 \mathrm{~g}$ of liver tissues were obtained and homogenized in $0.5 \mathrm{ml}$ of phosphate-buffered saline and then centrifuged at $2,000 \mathrm{x} \mathrm{g}$ for $15 \mathrm{~min}$ at $4^{\circ} \mathrm{C}$ to obtain the supernatant which was stored at $-70^{\circ} \mathrm{C}$. Catalase (CAT) activity and concentration of GSH (Cayman Chemical, Ann Arbor, MI, USA) were measured using assay kits, following the manufacturer's instructions using a Tecan spectrophotometer (Männedorf). For histochemistry analysis, epididymal adipose and liver tissues were fixed in $10 \%$ neutral formalin for $42 \mathrm{~h}$. The tissues portions were placed in cassettes and washed in three changes of phosphate buffered saline (30 min for each wash); cleared in two changes of xylene (30 min each) and embedded in 3 changes of paraffin ( $1 \mathrm{~h}$ each). The tissues were blocked in paraffin and cut to a $5-\mu \mathrm{m}$ thickness. The section tissues were stained with hematoxylin and eosin (H\&E) and viewed under a light microscope (Leica, Wetzlar, Germany). The epididymal adipocyte size was evaluated using an ImageJ software program (developed by the National Institutes of Health, Bethesda, MD, USA). In addition, an independent who was blinded to the grouping of the mice expert examined the stained liver sections.

Statistical analysis. Differences between groups were appraised by analysis of variance (ANOVA) followed by Duncan's multiple-range test. All data are given as the mean \pm SD (standard deviation). A P-value of $<0.05$ was set to indicate statistically significant results.

\section{Results}

Synergistic effects of PAG mixture on body weight, food intake, and food efficiency ratio. As shown in Fig. 1, mice fed with HFD (HFD control group) significantly gained more weight compared to the mice fed with normal laboratory diet (ND group). When mice were fed with HFD and administered with either PGE, AGE, GTE, PA mixture or PAG mixture, weight gain was significantly decreased compared to the HFD group. Of note, mice treated with the PAG mixture recorded the least amount of weight gain as compared to the other treatment groups.

The daily food intake in mice fed with HFD was significantly decreased compared to mice in the ND group. However, HFD mice administered with either PGE, AGE, GTE, PA mixture or PAG mixture, had a significant increase in the daily food intake compared to the HFD control group. Food efficiency ratio was also significantly increased in the HFD control group compared to the ND group. The PGE, AGE, GTE, PA mixture or PAG mixture treatment groups showed a significant reduction in food efficiency ratio compared to the HFD control group. The PAG mixture treatment group recorded the least food efficiency ratio.

Synergistic effects of PAG mixture on serum lipid profile, atherogenic index, and cardiac risk factor. As presented in Fig. 2, mice in the HFD control group showed a significant increase in serum triglyceride, total cholesterol, LDL-cholesterol, and HDL-cholesterol compared to the ND group. As compared to the mice in the HFD control group, all of the PGE, AGE, GTE, PA mixture or PAG mixture treatment groups showed a significant decrease in the levels of triglycerides (Fig. 2A). The total cholesterol (Fig. 2B), and LDL-cholesterol (Fig. 2C) were also decreased in all treatment groups except the AGE treatment group, with the PAG treatment group recording the least levels. The HDL-cholesterol level in serum was also decreased but their differences were not significant among the treatment groups (Fig. 2D).

The results of the atherogenic index and cardiac risk factor demonstrated that mice in the HFD control group had a significant increase in the atherogenic index and cardiac risk factors. However, only mice fed with HFD and administered with either GTE, PA mixture or PAG mixture had a significant reduction in the atherogenic index and cardiac risk factors, with the PAG mixture treatment group demonstrating better effects than the other treatment groups (Fig. 2E and F).

Synergistic effects of PAG mixture on energy balancing metabolism. As shown in Fig. 3, mice in the HFD control group recorded a significant increase in blood glucose level, compared to mice in the ND group. Only the PA mixture and PAG mixture treatment groups had a significant reduction in serum glucose levels compared to the mice in the HFD control group (Fig. 3A). Serum leptin levels were also significantly increased in mice of the HFD control group compared to the ND group. PGE, AGE, GTE, PA mixture or PAG mixture treatment groups recorded a significant decrease in leptin levels, compared to mice of the HFD control group (Fig. 3B). Similarly, insulin levels were significantly increased in mice of the HFD control group. However, the PGE, AGE, GTE, PA mixture or PAG mixture had the tendency to downregulate serum insulin levels (Fig. 3C). Among the treatment groups, the PAG mixture group appeared to have better effects on energy balancing metabolisms compared to the other groups.

Synergistic effects of PAG mixture on serum toxicity markers and liver oxidative stress. Mice fed with HFD resulted in a significant increase in the liver weight (Fig. 1) and serum levels of GOT and GPT compared to mice fed with a normal diet (Fig. 4A and B). A significant decrease in endogenous GSH antioxidant and catalase activities in the liver tissues were also observed in mice fed with HFD compare to mice in the ND group (Fig. 4C and D). Treatment with either the PGE, AGE, GTE, PA mixture or PAG mixture significantly decreased liver weight, with the PAG treatment group demonstrating better effects than the other treatment groups (Fig. 1). The serum GOT level was significantly decreased in the PA mixture and PAG mixture treatment group (Fig. 4A), while serum GPT level was significantly decreased in the PGE, GTE, PA mixture, and PAG mixture treatment groups (Fig. 4B). On the one hand, GSH antioxidant and catalase activities were significantly upregulated in all treated groups, with the PAG mixture treatment group demonstrating the best results (Fig. 4C and D). On the whole, the PGE, AGE, GTE, PA mixture or PAG mixture treatment showed no detectable adverse toxicity effects in the livers.

Synergistic effects of PAG mixture on adipose tissue and fat deposition. Mice fed with HFD resulted in a significant 

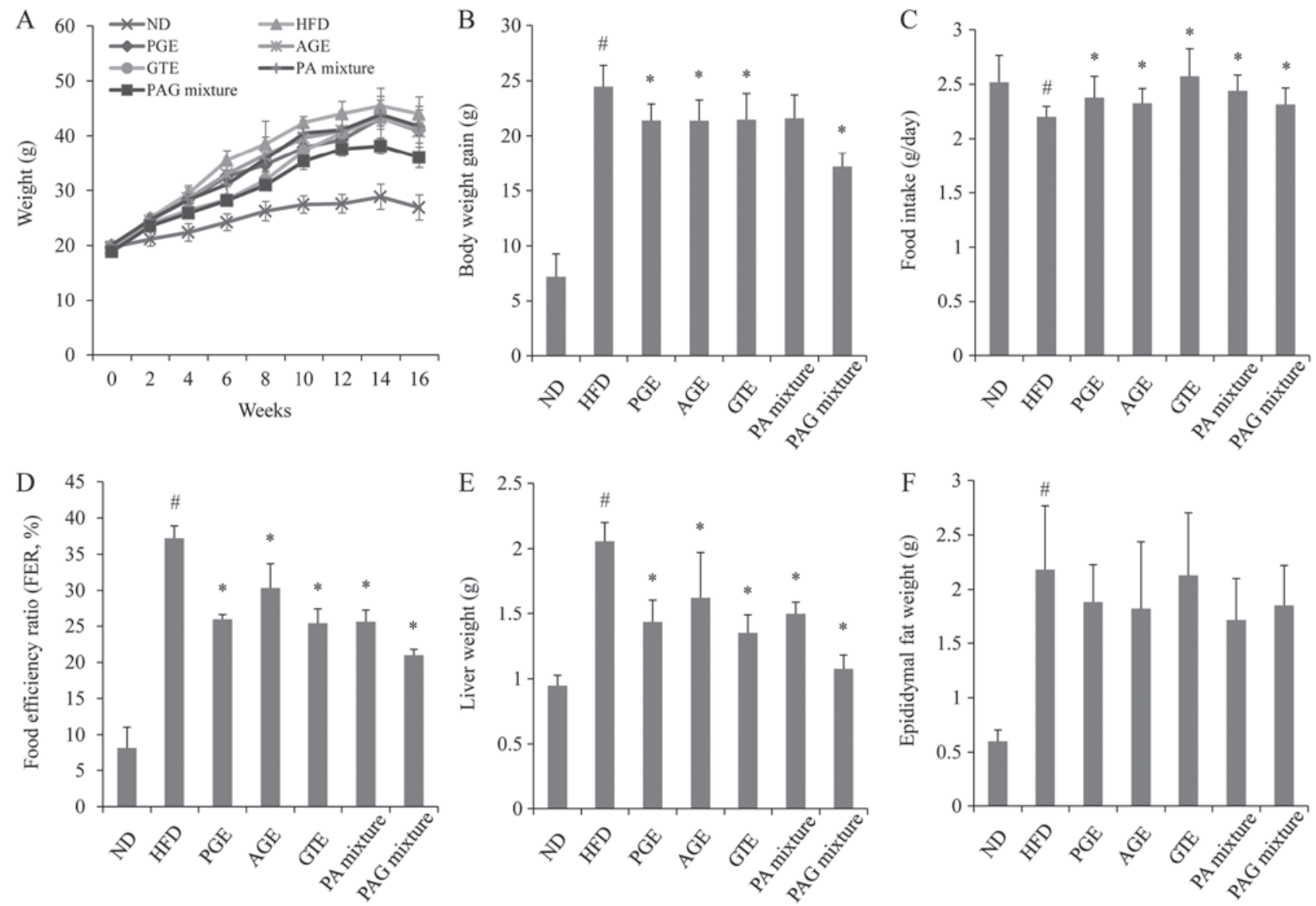

Figure 1. Synergistic effect of PAG mixture on (A) body weight, (B) weight gain, (C) food intake, (D) FER, (E) liver and (F) epididymal fat weight in HFD-induced obese mice. Data are presented as the mean \pm standard deviation $(n=5) .{ }^{*} \mathrm{P}<0.05$ vs. ND; ${ }^{*} \mathrm{P}<0.05$ vs. HFD group. ND, mice fed the normal diet; HFD, mice fed the high-fat diet; PGE, mice fed with HFD and administered with $200 \mathrm{mg} / \mathrm{kg} / \mathrm{day}$ of PGE. AGE, mice fed with HFD and administered with $200 \mathrm{mg} / \mathrm{kg} / \mathrm{day}$ of AGE; GTE, mice fed with HFD and administered with $200 \mathrm{mg} / \mathrm{kg} / \mathrm{day}$ of GTE; PA mixture, mice fed with HFD and administered with $100 \mathrm{mg} / \mathrm{kg} / \mathrm{day}$ of PGE + $100 \mathrm{mg} / \mathrm{kg} / \mathrm{day}$ of AGE; PAG mixture, mice fed with HFD and administered with $200 \mathrm{mg} / \mathrm{kg} / \mathrm{day}$ of PGE + AGE + GTE mixture (1:1:1 ratio); FER, food efficiency ratio=body weight gain (g/day)/food intake (g/day) x100.

increase in the epididymal fat weight compared to mice that received the normal diet (Fig. 1). However, mice fed with HFD and treated with either the PGE, AGE, GTE, PA mixture, or PAG mixture showed no significant decrease in the epididymal fat weight compared to the HFD control group (Fig. 1). To estimate the adipocyte size, using Image software, the diameter of adipocytes in H\&E stained sections were measured. The mice in the HFD control group showed a significant increase in adipocyte diameter size compared to the ND group. Of all the treatment groups, only the PAG group showed a significant decrease in adipocyte diameter compared to the HFD control group (Fig. 5A). The adipocyte size can be seen clearly in the histological sections presented in Fig. 5B.

Histological stain liver sections also showed that the liver of mice in the HFD control group had extensive lipid droplet accumulation compared to the ND group (Fig. 5C). Macrovesicular and micro lipid droplets could be seen in the liver sections of mice in the HFD control group thus demonstrating a typical fatty liver. All treatment groups showed less lipid droplet accumulation compared to the HFD control group. It is also of interest to note that the liver conditions of the PAG treatment group appeared to be close to those of the ND group (Fig. 5C).

\section{Discussion}

With the increasing global prevalence of obesity and its associated disorders, coupled with the fact that therapies designated for the prevention and treatment of obesity most often render patients with severe consequences, alternative anti-obesity therapies from natural products have taken the lead in modern day research with the sole aim of developing better therapies for the prevention and treatment of obesity and its associated disorders. In the present study, we investigated the synergistic effects of PGE, AGE, and GTE in obesity induced by HFD in mice. It was found that the PGE, AGE, GTE, and PA mixture decreased the body weight of mice that were fed with HFD. Although no significant difference was found in the epididymal adipose tissue of the HFD control group and the treatment groups, histological examinations of the epididymal tissues, and measurement of the diameters of the adipocyte in different microscopic fields revealed that the PAG mixture treatment group had reduced adipose cell size. The results obtained from the PAG mixture treatment appeared to be most effective in preventing weight gain and inhibiting epididymal adipocyte size expansion in the obese mice. Also, the results of the daily food intake and food efficiency ratio further suggest that PAG was most effective in preventing body weight gain among the treatment groups. From these results, it can be 

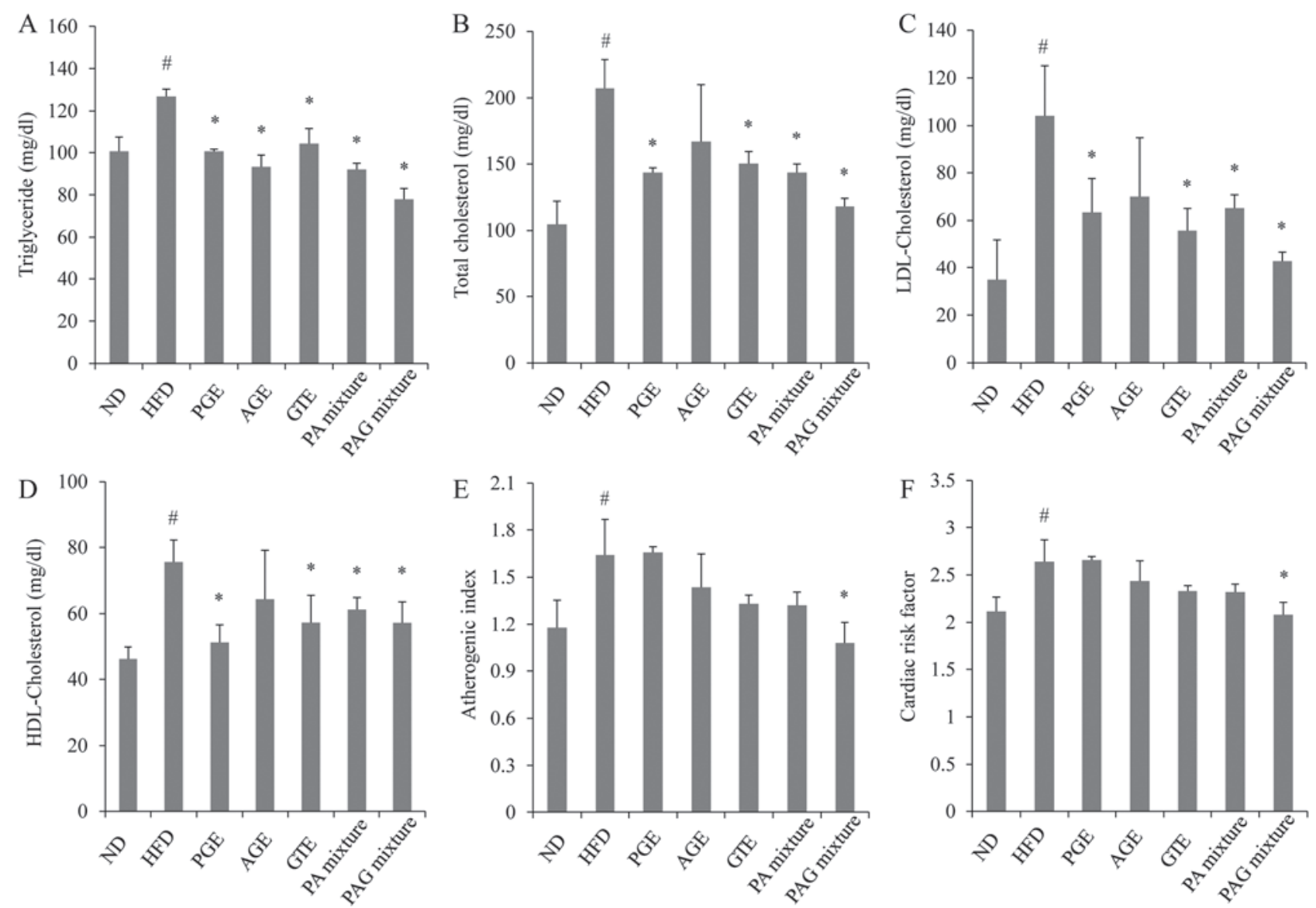

Figure 2. Synergistic effects of (A) TG, (B) TC, (C) LDL-C and (D) HDL-C PAG mixture on serum lipid profile, (E) atherogenic index and (F) cardiac risk factor in HFD-induced obesity in mice. Data are presented as the mean \pm standard deviation $(n=5)$. ${ }^{~} \mathrm{P}<0.05$ vs. ND; ${ }^{*} \mathrm{P}<0.05$ vs. HFD group. ND, mice fed the normal diet; HFD, mice fed the high-fat diet; PGE, mice fed with HFD and administered with $200 \mathrm{mg} / \mathrm{kg} / \mathrm{day}$ of PGE. AGE, mice fed with HFD and administered with $200 \mathrm{mg} / \mathrm{kg} / \mathrm{day}$ of AGE; GTE, mice fed with HFD and administered with $200 \mathrm{mg} / \mathrm{kg} / \mathrm{day}$ of GTE; PA mixture, mice fed with HFD and administered with $100 \mathrm{mg} / \mathrm{kg} / \mathrm{day}$ of PGE + $100 \mathrm{mg} / \mathrm{kg} /$ day of AGE. PAG mixture, mice fed with HFD and administered with $200 \mathrm{mg} / \mathrm{kg} / \mathrm{day}$ of PGE + AGE + GTE mixture (1:1:1 ratio); TG, triglyceride; TC, total cholesterol; LDL-C, low-density lipoprotein cholesterol; HDL-C, high-density lipoprotein cholesterol.
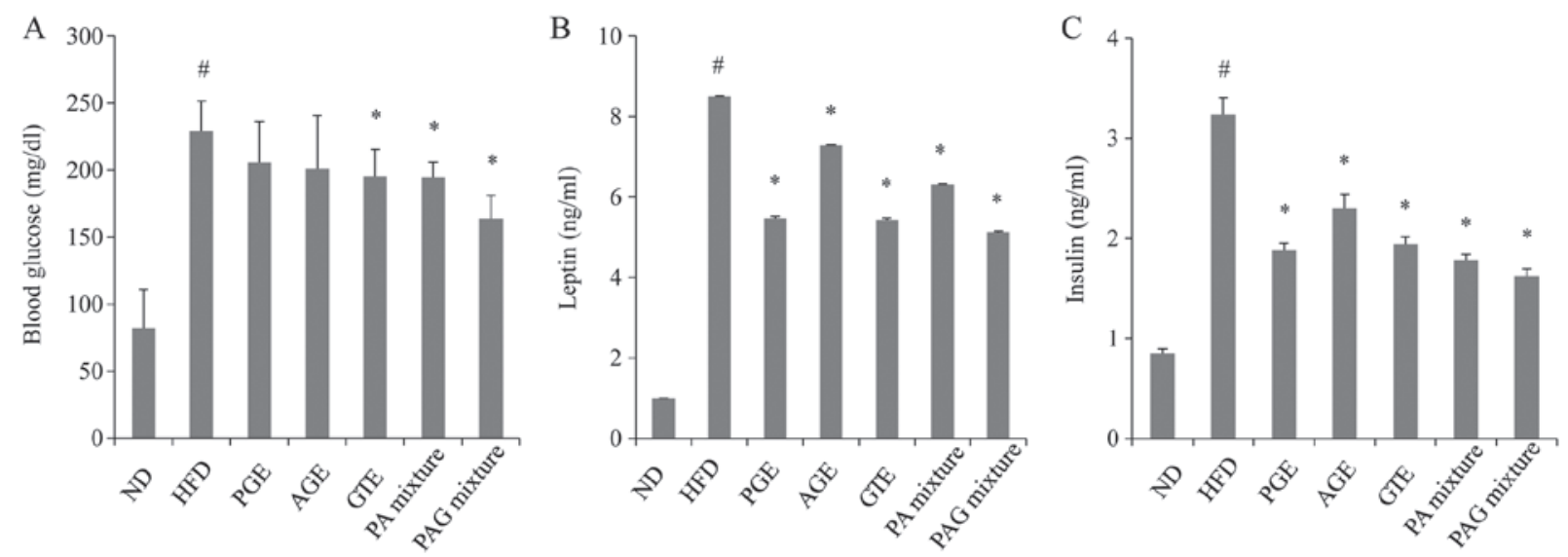

Figure 3. Synergistic effects of PAG mixture on energy balancing metabolism. (A) Blood glucose, (B) serum leptin and (C) serum insulin concentrations were measured. Data are presented as the mean \pm standard deviation $(n=5)$. " $\mathrm{P}<0.05$ vs. ND; "P<0.05 vs. HFD group. ND, mice fed the normal diet; HFD, mice fed the high-fat diet; PGE, mice fed with HFD and administered with $200 \mathrm{mg} / \mathrm{kg} / \mathrm{day}$ of PGE; AGE, mice fed with HFD and administered with $200 \mathrm{mg} / \mathrm{kg} / \mathrm{day}$ of AGE; GTE, mice fed with HFD and administered with $200 \mathrm{mg} / \mathrm{kg} / \mathrm{day}$ of GTE; PA mixture, mice fed with HFD and administered with $100 \mathrm{mg} / \mathrm{kg} / \mathrm{day}$ of PGE $+100 \mathrm{mg} / \mathrm{kg} / \mathrm{day}$ of AGE; PAG mixture, mice fed with HFD and administered with $200 \mathrm{mg} / \mathrm{kg} / \mathrm{day}$ of PGE + AGE + GTE mixture (1:1:1 ratio).

inferred that PAG treatment has the potential to be used as an anti-obesity agent for preventing weight gain and preventing an increase in adipocyte size in obesity and its associated disorders.
In animals as well as in humans, obesity or a high-fat diet has been shown to influence lipid dynamics that result in or increase the risk of cardiovascular diseases. In this study, 

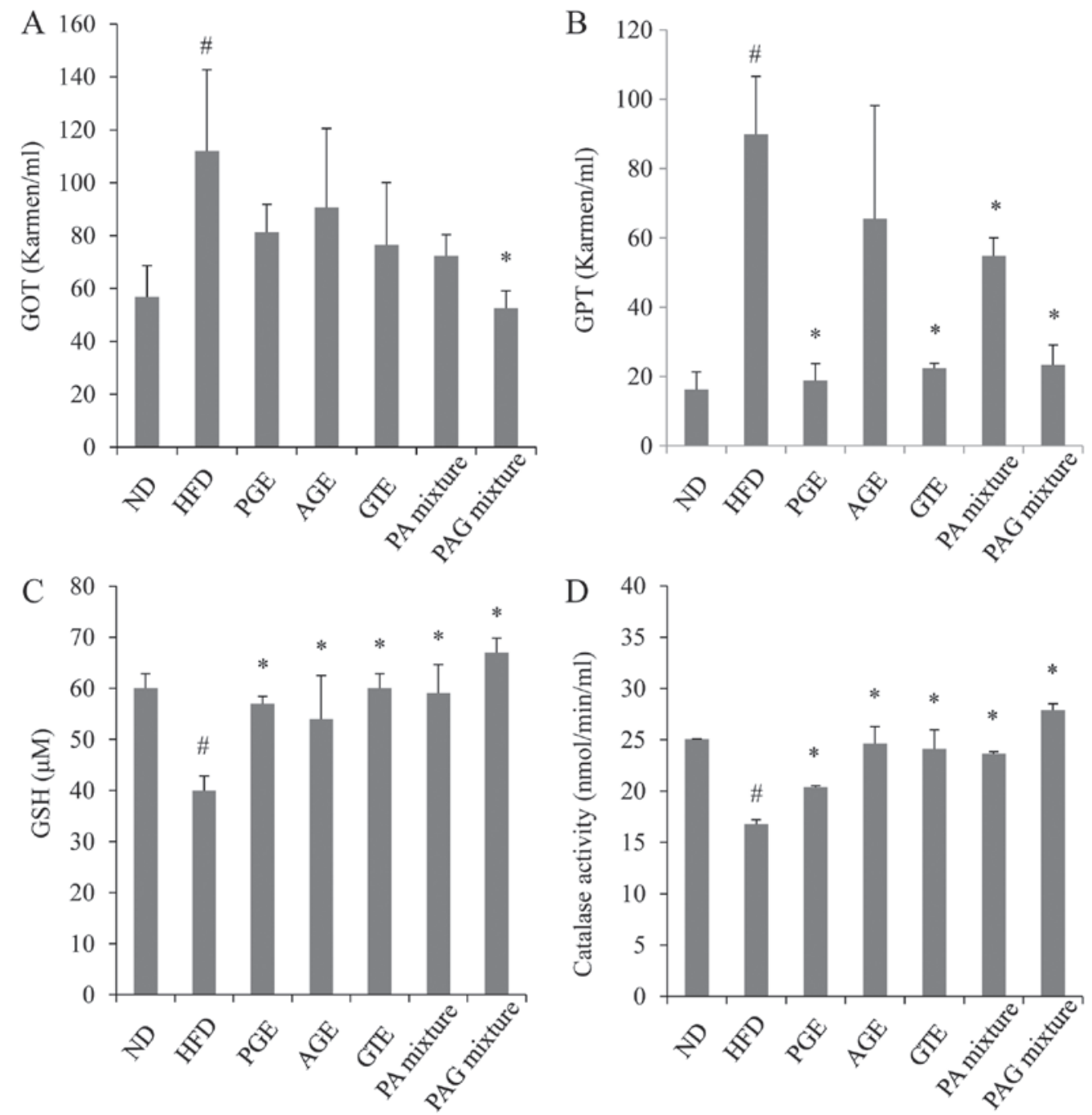

Figure 4. Synergistic effects of PAG mixture on serum toxicity markers and liver oxidative stress. (A) Serum GOT, (B) serum GPT, (C) liver GSH and (D) liver catalase activities were measured. Data are presented as the mean \pm standard deviation $(n=5)$. ${ }^{\#}<0.05$ vs. ND; ${ }^{*} \mathrm{P}<0.05$ vs. HFD group. ND, mice fed the normal diet; HFD, mice fed the high-fat diet; PGE, mice fed with HFD and administered with $200 \mathrm{mg} / \mathrm{kg} / \mathrm{day}$ of PGE; AGE, mice fed with HFD and administered with $200 \mathrm{mg} / \mathrm{kg} / \mathrm{day}$ of AGE; GTE, mice fed with HFD and administered with $200 \mathrm{mg} / \mathrm{kg} / \mathrm{day}$ of GTE; PA mixture, mice fed with HFD and administered with $100 \mathrm{mg} / \mathrm{kg} / \mathrm{day}$ of PGE $+100 \mathrm{mg} / \mathrm{kg} / \mathrm{day}$ of AGE; PAG mixture, mice fed with HFD and administered with $200 \mathrm{mg} / \mathrm{kg} / \mathrm{day}$ of PGE + AGE + GTE mixture (1:1:1 ratio).

obesity led to an increment of serum lipid parameters such as TG, total cholesterol, LDL, and HDL. These disturbances in the lipid dynamics exposed the mice to the risk of developing cardiovascular diseases as revealed by the atherogenic index and cardiac risk factor data of this study. The study also showed that PGE, AGE, GTE, PA mixture, and PAG mixtures decreased the serum lipid parameters thereby decreasing the risk of cardiovascular disease, with the PAG mixture demonstrating the overall best effects. Previous studies have revealed the presence of hypolipidaemic compounds in PGE, AGE, and GTE $(16,21,27)$. The effects of these extracts and their combinations could act by directly preventing obesity and hence lipid serum levels or by decreasing cholesterol absorption or better still interfering in triglyceride or cholesterol synthesis. A study had earlier reported that phenols in apples were responsible for hypolipidemic and antiatherogenic in rats by suppressing cholesterol absorption while promoting its catabolism (28).

Leptin and insulin among other hormones are key obesity markers that correlate positively with adiposity and an increase in fat mass and are involved in the regulation of appetite and satiety, thus affecting energy metabolism (29). Also, leptin and insulin resistance is seen in obesity and its leads to hyperinsulinemia and hyperleptinemia $(30,31)$. Thus, the normalization of these obesity-related parameters will lead to fat and glucose metabolism thus providing useful methods for treating obesity and its related complications. In the present study, serum insulin and leptin were increased with HFD treatment. HFD has been reported to increase insulin and leptin levels, causing hyperinsulinemia and hyperleptinemia (32). It was also revealed in this study that treatment with PGE, AGE, GTE, PA mixture, and PAG mixtures suppressed the increase in insulin and leptin levels with PAG mixture demonstrating the overall best results. The effects of these extracts in decreasing insulin and leptin levels might also be responsible for the decrease in glucose levels seen with the extract treatment, especially with the PAG mixture treatment group. Several reports have shown a reduction in body weight gain with HFD treatment of mice through leptin modulation (33-35). It is also of interest to note that insulin determines 


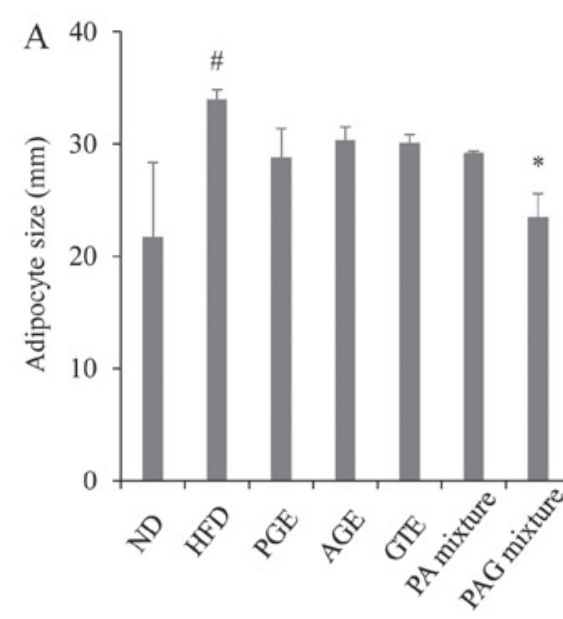

B
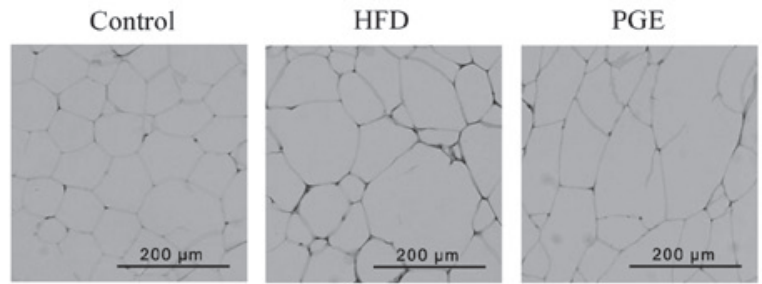

AGE

GTE
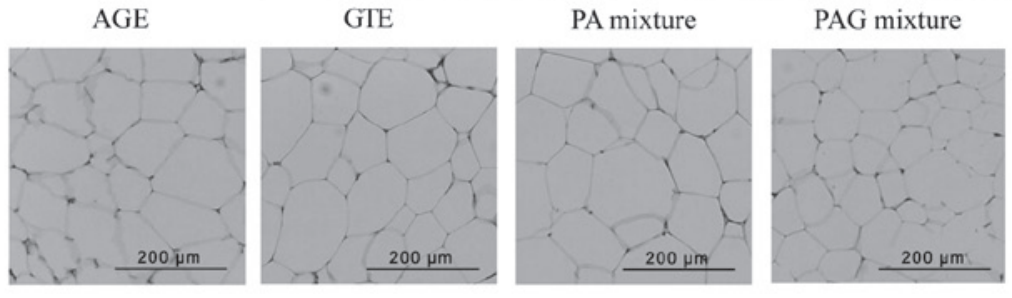

$\mathrm{C}$
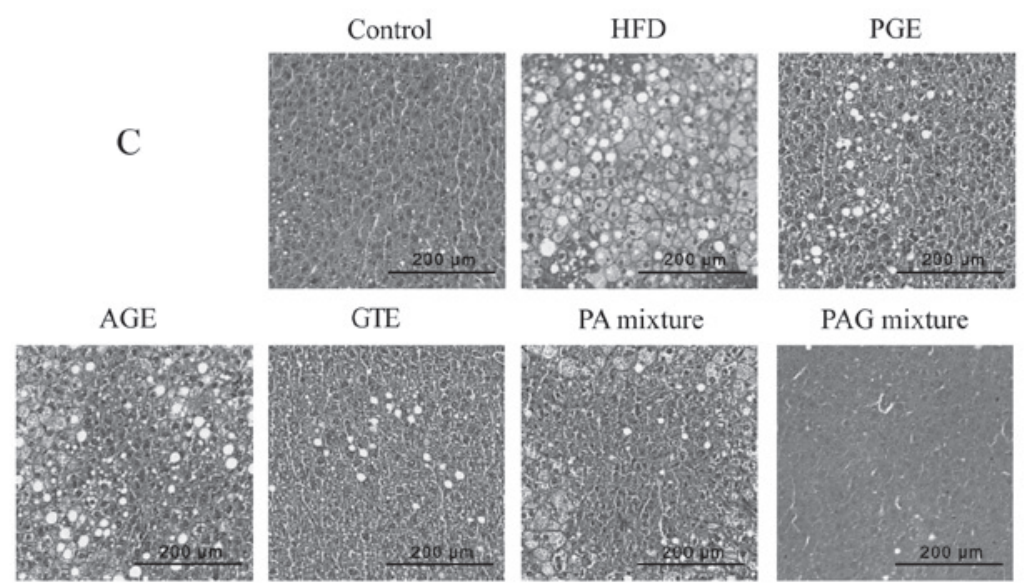

GTE

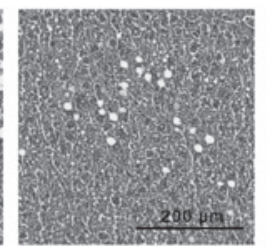

PA mixture

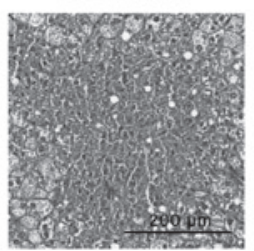

PAG mixture

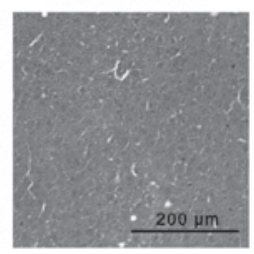

Figure 5. Synergistic effects of PAG mixture on adipose tissue and fat deposition. (A) The diameter of adipocytes in a particular field in H\&E stained sections were measured using ImageJ software. (B) Representative photographs of H\&E stained epididymal adipose tissue showing adipocyte size. (C) Representative photographs showing fat accumulation (hepatic steatosis) in H\&E-stained liver tissue sections. " $\mathrm{P}<0.05$ vs. ND; "P<0.05 vs. HFD group; magnification, $\mathrm{x} 100$. ND, mice fed the normal diet; HFD, mice fed the high-fat diet; PGE, mice fed with HFD and administered with $200 \mathrm{mg} / \mathrm{kg} / \mathrm{day}$ of PGE. AGE, mice fed with HFD and administered with $200 \mathrm{mg} / \mathrm{kg} / \mathrm{day}$ of AGE; GTE, mice fed with HFD and administered with $200 \mathrm{mg} / \mathrm{kg} / \mathrm{day}$ of GTE; PA mixture, mice fed with HFD and administered with $100 \mathrm{mg} / \mathrm{kg} / \mathrm{day}$ of PGE $+100 \mathrm{mg} / \mathrm{kg} / \mathrm{day}$ of AGE. PAG mixture, mice fed with HFD and administered with $200 \mathrm{mg} / \mathrm{kg} / \mathrm{day}$ of PGE + AGE + GTE mixture (1:1:1 ratio); H\&E, haemotoxylin and eosin.

leptin levels (32). Therefore, it can be concluded that a significant decrease in insulin level may have resulted in the suppression of leptin and hence glucose levels with the extracts treatment.

A high-fat diet is also well known to increase liver weight probably through fatty acid deposition, causes liver injury and also induces oxidative burden in mice liver. Consistently, feeding mice with HFD led to higher liver weight, while administration of the PGE, AGE, GTE, PA mixture, and PAG mixtures led to a decrease in liver weight. Histological findings using H\&E staining revealed severe hepatic steatosis in HFD-fed mice. The presence of macrovesicular and micro lipid droplets could be seen in stained sections. In addition, HFD resulted in liver oxidative stress and injury as evidenced by enhanced GOT, GPT, and diminished catalase activity and GSH levels. Administration of PGE, AGE, GTE, PA mixture, and in particular PAG mixtures to mice fed with HFD reduced fatty acid deposition in the liver; reduced GOT and GPT; and up-regulated catalase activity and GSH levels in the mice. These results further suggest that PGE, AGE, and GTE combinations possess liver-protective actions.

The observed effects of PAG mixtures on weight gain, adipocyte size, lipid profiles, obesity-related hormones, and liver protection in our study were in compliance with reports from other studies. Varying combinations of Phyllostachys pubescens leaf extract and Scutellaria baicalensis root extract significantly reduced weight gain, adipose tissue weight, size of adipocytes, and the levels of glucose, leptin, and lipid profile in serum, and fat accumulation in the liver (36). Treatment with mixtures of Salacia reticulate extract and cyclodextrin also significantly suppresses body weight gain, visceral fat mass plasma leptin, and TG levels of rats fed with HFD (37). Here, we hypothesized that the potential mechanism of action of these extracts could involve increasing energy expenditure, enhancing lipolysis, preventing energy intake, and elevating fatty acid oxidation-related genes especially as one of the extracts used in this study (Green tea) had previously been shown to regulated these parameters in previous studies $(9,38)$. The synergistic effects that were seen in this study could have arisen from an increase in the number or amount of antiobesity constituents as a result of combining the three extracts. Also, an important observation in this study was the fact that the combination of the three extracts did not demonstrate any adverse effects (evidenced by no mouse death recorded) as seen with drug-drug interaction in combinational therapies. 
In conclusion, oral administration of PAG mixture significantly reduced body weight, adipocyte size, serum triglyceride, total cholesterol, LDL cholesterol and leptin, insulin and glucose levels in high-fat-diet-induced obese mice. The mixed extract also decreased the serum levels of GOT and GPT, upregulated catalase activity and GSH level, thus preventing liver injury. Therefore, it can be assumed that a combination of Platycodon grandiflorum, Apium graveolens, and green tea exert anti-obesity effects. The overall findings of this study indicate that the PAG mixture is worthy of further investigation as a potential anti-obesity agent. As a limitation to the present study, multiple ratios of the extracts were not tested to determine the optimal ratio for better efficacy.

\section{Acknowledgements}

Not applicable.

\section{Funding}

This research was supported by a grant (grant no. 20170914C1-014) from the Jeonbuk Research \& Development Program funded by Jeonbuk Province.

\section{Availability of data and materials}

The datasets used and/or analyzed data during the study are available from the corresponding author on reasonable request.

\section{Authors' contributions}

BOC and SIJ designed the research. HJK, DNC, JYS, JSK and SJK performed the research. BOC, JC and SIJ analyzed the research data. BOC, JC, SIJ and DNC wrote the manuscript draft. BOC, SIJ and DNC reviewed and edited the final manuscript. BOC managed the research project. All authors read and approved the final manuscript.

\section{Ethics approval and consent to participate}

The mice were handled and experiments were carried out based on Jeonju University Institutional Animal Care and Use Committee guidelines with permission to carry out the experiment obtained from Jeonju University (approval no. JJU-IACUC-2018-8).

\section{Patient consent for publication}

Not applicable.

\section{Competing interests}

The authors declare that they have no competing interests.

\section{References}

1. Jane L, Atkinson G, Jaime V, Hamilton S, Waller G and Harrison S: Intermittent fasting interventions for the treatment of overweight and obesity in adults aged 18 years and over: A systematic review protocol. JBI Database System Rev Implement Rep 13: 60-68, 2015.

2. WHO: Obesity and overweight. February 16, 2018.
3. Bloomgarden ZT: Obesity, hypertension, and insulin resistance. Diabetes Care 25: 2088-2097, 2002.

4. Gallagher EJ and LeRoith D: Obesity and Diabetes: The increased risk of cancer and cancer-related mortality. Physiol Rev 95: 727-748, 2015.

5. Kushner RF: Medical management of obesity. Semin Gastrointest Dis 13: 123-132, 2002.

6. Connolly HM, Crary JL, McGoon MD, Hensrud DD, Edwards BS Edwards WD and Schaff HV: Valvular heart disease associated with fenfluramine-phentermine. N Engl J Med 337: 581-588, 1997.

7. Glazer G: Long-term pharmacotherapy of obesity 2000: A review of efficacy and safety. Arch Intern Med 161: 1814-1824, 2001.

8. Powell AG, Apovian CM and Aronne LJ: New drug targets for the treatment of obesity. Clin Pharmacol Ther 90: 40-51, 2011.

9. Huang J, Wang Y, Xie Z, Zhou Y, Zhang Y and Wan X: The anti-obesity effects of green tea in human intervention and basic molecular studies. Eur J Clin Nutr 68: 1075-1087, 2014.

10. Suzuki T, Pervin M, Goto S, Isemura $M$ and Nakamura $Y$ : Beneficial effects of tea and the green tea catechin epigallocatechin-3-gallate on obesity. Molecules 21: pii: E1305, 2016.

11. Ma G, Guo W, Zhao L, Zheng Q, Sun Z, Wei J, Yang J and Xu X: Two new triterpenoid saponins from the root of Platycodon grandiflorum. Chem Pharm Bull (Tokyo) 61: 101-104, 2013.

12. Lee JY, Hwang WI and Lim ST: Antioxidant and anticancer activities of organic extracts from Platycodon grandiflorum A. De Candolle roots. J Ethnopharmacol 93: 409-415, 2004

13. Lee KJ, You HJ, Park SJ, Kim YS, Chung YC, Jeong TC and Jeong HG: Hepatoprotective effects of Platycodon grandiflorum on acetaminophen-induced liver damage in mice. Cancer Lett 174: 73-81, 2001.

14. Jeong CH, Choi GN, Kim JH, Kwak JH, Kim DO, Kim YJ and Heo HJ: Antioxidant activities from the aerial parts of Platycodon grandiflorum. Food Chem 118: 278-282, 2010.

15. Ahn KS, Noh EJ, Zhao HL, Jung SH, Kang SS and Kim YS: Inhibition of inducible nitric oxide synthase and cyclooxygenase II by Platycodon grandiflorum saponins via suppression of nuclear factor-kappaB activation in RAW 264.7 cells. Life Sci 76: 2315-2328, 2005.

16. Zhao HL, Harding SV, Marinangeli CP, Kim YS and Jones PJ: Hypocholesterolemic and anti-obesity effects of saponins from Platycodon grandiflorum in hamsters fed atherogenic diets. J Food Sci 73: H195-H200, 2008.

17. Mencherini T, Cau A, Bianco G, Della Loggia R, Aquino RP and Autore G: An extract of Apium graveolens var. dulce leaves: Structure of the major constituent, apiin, and its anti-inflammatory properties. J Pharm Pharmacol 59: 891-897, 2007.

18. Momin RA and Nair MG: Mosquitocidal, nematicidal, and antifungal compounds from Apium graveolens L. seeds. J Agric Food Chem 49: 142-145, 2001.

19. Baananou S, Bouftira I, Mahmoud A, Boukef K, Marongiu B and Boughattas NA: Antiulcerogenic and antibacterial activities of Apium graveolens essential oil and extract. Nat Prod Res 27: 1075-1083, 2013

20. Kooti W and Daraei N: A review of the antioxidant activity of celery (Apium graveolens L). J Evid Based Complementary Altern Med 22: 1029-1034, 2017.

21. Jung UJ, Cho YY and Choi MS: Apigenin ameliorates dyslipidemia, hepatic steatosis and insulin resistance by modulating metabolic and transcriptional profiles in the liver of high-fat diet-induced obese mice. Nutrients 8: E305, 2016.

22. Liu G, Zhuang L, Song D, Lu C and Xu X: Isolation, purification, and identification of the main phenolic compounds from leaves of celery (Apium graveolens L. var. dulce Mill./Pers.). J Sep Sci 40: 472-479, 2017.

23. Chantre P and Lairon D: Recent findings of green tea extract AR25 (Exolise) and its activity for the treatment of obesity. Phytomedicine 9: 3-8, 2002.

24. Brown AL, Lane J, Holyoak C, Nicol B, Mayes AE and Dadd T: Health effects of green tea catechins in overweight and obese men: A randomised controlled cross-over trial. Br J Nutr 106: 1880-1889, 2011

25. Cardoso GA, Salgado JM, Cesar Md C and Donado-Pestana CM: The effects of green tea consumption and resistance training on body composition and resting metabolic rate in overweight or obese Women. J Med Food 16: 120-127, 2013.

26. Singhal K, Raj N, Gupta K and Singh S: Probable benefits of green tea with genetic implications. J Oral Maxillofac Pathol 21: 107-114, 2017. 
27. Ahmad RS, Butt MS, Sultan MT, Mushtaq Z, Ahmad S, Dewanjee S, De Feo V and Zia-Ul-Haq M: Preventive role of green tea catechins from obesity and related disorders especially hypercholesterolemia and hyperglycemia. J Transl Med 13: 79, 2015.

28. Osada K, Suzuki T, Kawakami Y, Senda M, Kasai A, Sami M, Ohta Y, Kanda T and Ikeda M: Dose-dependent hypocholesterolemic actions of dietary apple polyphenol in rats fed cholesterol. Lipids 41: 133-139, 2006.

29. Staiger H and Haring HU: Adipocytokines: Fat-derived humoral mediators of metabolic homeostasis. Exp Clin Endocrinol Diabetes 113: 67-79, 2005.

30. Klok MD, Jakobsdottir S and Drent ML: The role of leptin and ghrelin in the regulation of food intake and body weight in humans: A review. Obes Rev 8: 21-34, 2007.

31. Könner AC, Hess S, Tovar S, Mesaros A, Sánchez-Lasheras C, Evers N, Verhagen LA, Brönneke HS, Kleinridders A, Hampel B, et al: Role for insulin signaling in catecholaminergic neurons in control of energy homeostasis. Cell Metab 13: 720-728, 2011.

32. Harte RA, Kirk EA, Rosenfeld ME and LeBoeuf RC: Initiation of hyperinsulinemia and hyperleptinemia is diet dependent in C57BL/6 mice. Horm Metab Res 31: 570-575, 1999.
33. Sasaki T: Age-associated weight gain, leptin, and SIRT1: A possible role for hypothalamic SIRT1 in the prevention of weight gain and aging through modulation of leptin sensitivity. Front Endocrinol (Lausanne) 6: 109, 2015.

34. Myers MG Jr, Leibel RL, Seeley RJ and Schwartz MW: Obesity and leptin resistance: Distinguishing cause from effect. Trends Endocrinol Metab 21: 643-651, 2010.

35. Carter S, Caron A, Richard D and Picard F: Role of leptin resistance in the development of obesity in older patients. Clin Interv Aging 8: 829-844, 2013.

36. Kim DS, Kim SH and Cha J: Antiobesity effects of the combined plant extracts varying the combination ratio of phyllostachys pubescens leaf extract and scutellaria baicalensis root extract. Evid Based Complement Alternat Med 2016: 9735276, 2016

37. Kishino E, Ito T, Fujita K and Kiuchi Y: A mixture of the Salacia reticulata (Kotala himbutu) aqueous extract and cyclodextrin reduces the accumulation of visceral fat mass in mice and rats with high-fat diet-induced obesity. J Nutr 136: 433-439, 2006.

38. Rains TM, Agarwal S and Maki KC: Antiobesity effects of green tea catechins: A mechanistic review. J Nutr Biochem 22: 1-7, 2011. 